\title{
Pattern of Mandibular Third Molar Impaction in North-Central Nigeria: Panoramic Radiographic Assessment
}

\section{Seidu Adebayo Bello ${ }^{1,2}$ and Nathan Ukuoghene Ikimi ${ }^{1,2 *}$}

${ }^{1}$ Dental and Oral Maxillofacial Surgery Department, State House Medical Centre, State House, Aso Rock, Abuja FCT, Nigeria

${ }^{2} \mathrm{QH}$ Specialist Dental Clinics and Research Centre/International Craniofacial Academy, Gwarinpa, Abuja FCT, Nigeria

*Corresponding Author: Nathan Ukuoghene Ikimi, Dental and Oral Maxillofacial Department, State House Medical Centre, Aso Rock, Abuja FCT, Nigeria.
Received: March 02, 2021

Published: March 22, 2021

(C) All rights are reserved by Seidu Adebayo

Bello and Nathan Ukuoghene Ikimi.

\section{Abstract}

The third molar is the most common tooth in the mouth that fails to erupt partially or completely into its functional position and this could be because of an impediment on the eruption path. Management of impacted third molar is usually by a surgical procedure extraction and successful treatment is enhanced with the aid of a radiograph which is either the periapical x-ray or the panoramic radiograph. This study reports on a large population of patients, using the panoramic radiograph to evaluate and compare with the periapical radiograph the various pattern of the impacted mandibular third molar presented in north central Nigeria.

A retrospective examination of digital panoramic radiographs obtained from patients who had surgical extractions of impacted mandibular molars between March 2016 to April 2020. The data obtained were analysed using the Statistical Packages for the Social Sciences (SPSS) version 20. Chi-square test was done to determine statistical significance which was set as $\mathrm{P}<0.05$.

There were $366(55.8 \%)$ male and 289 (44.1\%) females, with an age range of 16 to 70years and a mean age of $34 \pm 12.5$ years. Impaction was found on one side of the mandible in $30.3 \%$ and on both sides of the mandible in $69.5 \%$ of the patients and the most common type of impaction according to Winter's classification was mesioangular impaction and found more common among males in this study at $43.4 \%$.

Our results here gave better clarity with the use of the panoramic radiographs and therefore strongly recommends the orthopantomogram (OPG) before any mandibular $3^{\text {rd }}$ molar extraction is done.

Keywords: Impacted Third Molar; Orthopantomogram; Panoramic; Periapical; Pattern

\section{Abbreviations}

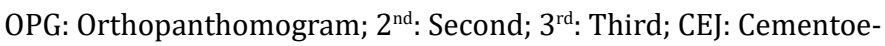
namel Junction; SPSS: Statistical Packages for the Social Sciences

\section{Introduction}

An impacted tooth is one that fails to erupt partially or completely into its functional position in the dental arch [1,2]. This is usually a pathological failure and might be because of an impediment on the eruption path created by soft tissue, dental hard tissue, or bone, resulting in some oral health challenges such as pericoronitis, cysts formation, root resorption of adjacent tooth or even neoplasm [3-5]. Eshghpour., et al. reported on the uniqueness of the third molar as being the most common tooth to be impacted [6] 
and this impaction could compromise the strength of the angle of the mandible resulting in a fracture of the mandible as a complication [5]. Symptomatic treatment of impacted third molar ( $\left.3^{\text {rd }}\right)$ by a surgical extraction and careful wound closure procedure is usually done by a dental surgeon who has received some training in impacted mandibular third molar ( $3^{\text {rd }}$ molar) surgical extraction so that post-extraction complications are reduced or avoided [7].

The impacted mandibular $3^{\text {rd }}$ molar has various classifications, one of which is the Winter's classification [8], while another is Pell and Gregory's [9] classification. A good understanding of the classifications of impacted mandibular $3^{\text {rd }}$ molar is particularly important since they can help the clinician to make treatment modification for anticipated challenges [10] which could affect post-operative morbidity of the surgery [11]. Winter's classification of the impacted mandibular $3^{\text {rd }}$ molar is based on the level of impaction in relationship to an imaginary line drawn from the occlusal plane of the first and second $\left(2^{\text {nd }}\right)$ molar to the retromolar region of the mandible as shown in a dental radiograph [8]. Thus, the impaction is classified as mesioangular, distoangular, buccolingual, ectopic, vertical, and horizontal. Furthermore, Pell and Gregory [9] classified the impacted mandibular $3^{\text {rd }}$ molar based on the level of the cementoenamel junction (CEJ) of the $2^{\text {nd }}$ molar. When the impacted $3^{\text {rd }}$ molar is above the CEJ of the $2^{\text {rd }}$ molar it is describes as Level A; when the impacted $3^{\text {rd }}$ molar is below the CEJ of the $2^{\text {rd }}$ molar and is partially buried in the alveolar bone, it is known as Level $\mathrm{B}$; when the impacted $3^{\text {rd }}$ molar is completely buried in the bone, it is known as Level C. Additionally, the relationship of the impacted $3^{\text {rd }}$ molar to the anterior border of the ramus of mandibular with the available space, distal to the $2^{\text {nd }}$ molar was also used by Pell and Gregory to classify the impacted mandibular $3^{\text {rd }}$ molar. When the space is sufficient for the $3^{\text {rd }}$ molar to erupt, it is known as Class 1 ; when the $3^{\text {rd }}$ molar has a little space to partially erupt, it is known as Class 2 and when there is no available space for the eruption of the $3^{\text {rd }}$ molar, it is called Class 3 .

Studies in different regions of the world has described various patterns of mandibular $3^{\text {rd }}$ molar impactions with the aid of either the periapical radiograph or the orthopantomograpm (OPG). In the Northeast region of Iran, a study using the OPG reported that mesioangular impaction of mandibular $3^{\text {rd }}$ molar was significantly higher at $48.67 \%$ than other types of mandibular $3^{\text {rd }}$ molar impaction [5]. Another study in Southeast region of Iran using the OPG reported a prevalence of $44.3 \%$ for mesioangular mandibular $3^{\text {rd }}$ molar impaction as being the highest type of impaction [12]. Hassan's report from the Western region of Saudi Arabia, also using the OPG ranked mesioangular as the most common types of mandibular $3^{\text {rd }}$ molar impaction at prevalence of $33.5 \%$ [13]. Passi., et al. using a combination of OPG and periapical radiograph among Delhi-National Capital Region population described the mesioangular impactions at $49.2 \%$ as the most common type of $3^{\text {rd }}$ molar impaction with more males $(60.8 \%)$ having $3^{\text {rd }}$ molar impaction than females (39.2\%) [14]. Furthermore, report on a Singapore Chinese population, using the OPG stated that the mesioangular pattern of $3^{\text {rd }}$ molar impaction was the most common type of impaction occurring however, more females $(56 \%)$ than males $(44 \%)$ had $3^{\text {rd }}$ molar impaction [15]. On the other hand, a male to female ratio of 1.2:1, in 3rd molar impactions was reported in Dar es Salaam, Tanzania while using the OPG with mesioangular $3^{\text {rd }}$ molar impaction reported as the most common type of impaction at 738 (76\%) [16].

Similar studies in Nigeria, has described the patterns of various types of $3^{\text {rd }}$ impaction using the periapical radiographs. Osunde and Bassey reported from South-south Nigeria a prevalence of $44.9 \%$ for mesioangular, $21.2 \%$ for distoangular, $28.2 \%$ for horizontal and $5.1 \%$ for vertical types of $3^{\text {rd }}$ molar impactions [1]. Gbotolorun., et al. reported a prevalence of $53.4 \%$ for mesioangular impaction of the $3^{\text {rd }}$ molar in South-west Nigeria [14,17]. Adelusi and Okoje also reported a high prevalence for mesioangular impaction in Southwest Nigieria $[15,18]$ and a similar result of high prevalence was reported from the North-western region of Nigeria [16,19].

The orthopantomogram (OPG) which is a panoramic single radiograph of the mandible and the maxilla is the standard diagnostic tool recommended to evaluate the impacted $3^{\text {rd }}$ molar especially with its ability to reveal the position of the inferior alveolar canal in relationship with the roots of the impacted $3^{\text {rd }}$ molar and this information is important preoperatively to reduce the risk of nerve injury $[17,20]$. If the radiological markers on the panoramic radiograph shows that the roots of the impacted $3^{\text {rd }}$ molar and mandibular channel are in proximity, then it is recommended that additional investigation should be done using the Cone beam computer tomography (CBCT) where cross-sectional and multiplanar reconstruction is obtained to determine the relationship of vascular-nerve bundle and the root [21-24]. However, with the modern development of the use of the OPG in the management of the im- 
pacted mandibular $3^{\text {rd }}$ molar, there has not been any report to the best of our knowledge from the North-central region of Nigeria that used the OPG to describe the pattern of $3^{\text {rd }}$ molar impaction.

\section{Aim of the Study}

The focus of this study is therefore to report on a large population of patients using the OPG to get panoramic radiographs for better evaluation and appreciation of the various pattern presented by the impacted $3^{\text {rd }}$ molar.

\section{Materials and Methodology}

This is retrospective examination of digital panoramic radiographs obtained from patients who had surgical extractions of impacted mandibular molars at the State House Clinic Asokoro Abuja and QH Specialist Dental Clinics and Research Centre at Gwaripa, Abuja between March 2016 to April 2020. Panoramic radiographs of patients below the age of 15 years, radiographs indicating missing second molars and those with artifacts were all excluded from this examination. The radiographs were obtained at both centres with the ORTHOPHOS XGPlusDS/Ceph (Sirona Dental systems $\mathrm{GmbH}$, Bensheim, Germany) digital panoramic machine (tube voltage: 60 - $90 \mathrm{kV}$, tube current: 3 - $16 \mathrm{~mA}$, total filtration of X-ray tube assembly: $>2.5 \mathrm{~mm}$ and magnification coefficient: 1.25$)$. Obtained from their medical records were information such as age, gender, residence, presence of caries in the second molar, past dental history, and indication for extraction. Winter's Classification [8] with Pell and Gregory's classifications [9] were both used by a trained, calibrated examiner who is an oral maxillofacial surgeon to interpret all digital panoramic radiographs and immediately record the interpretations in an already designed excel spread sheet for this research. The data obtained were analysed using the Statistical Packages for the Social Sciences (SPSS) version 20 (SPSS-Inc., Chicago, US). Frequencies and percentages were used for categorical variables while mean and standard deviation for the continuous variable. Chi-square test was done to determine statistical significance which was set as $\mathrm{P}<0.05$.

Figure 1 Illustrations of $3^{\text {rd }}$ molar impaction according to Winter's classification; Pell and Gregory's classification.

Evaluation using Pell and Gregory classification would be done in this study according to the position of the impacted mandibular $3^{\text {rd }}$ molar in relationship with the CEJ of the $2^{\text {nd }}$ molar.

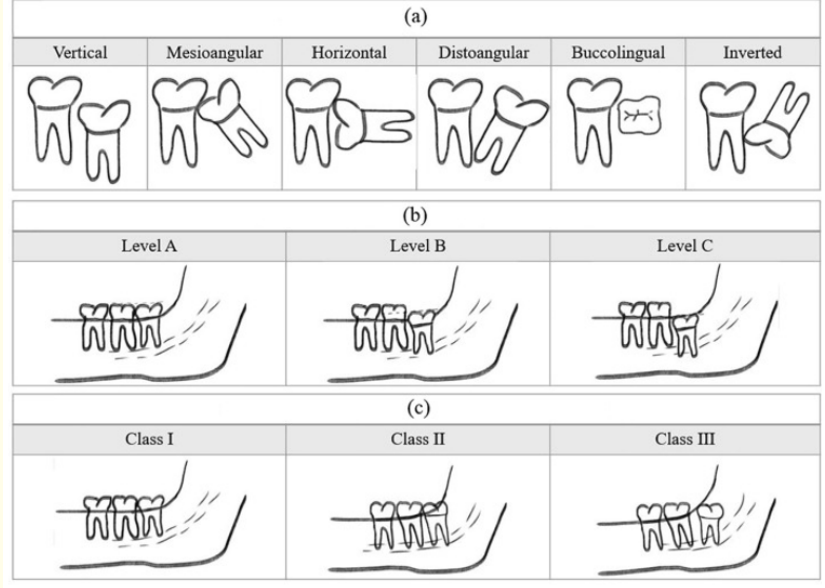

Figure 1: (a) Winter's classification for impacted $3^{\text {rd }}$ mandibular molar showing the various types of angulation seen on OPG. (b) Pell and Gregory's Classification of the impacted $3^{\text {rd }}$ mandibular molar depth in relation to the cementoenamel junction (CEJ) of the second molar. (c) Pell and Gregory's Classification of impacted 3rd mandibular molars displaying the molar relationship with the anterior border of the Ramus.

Images: Courtesy of Alfadil I and Almajed E [25].

Position A) When occlusal level of impacted mandibular $3^{\text {rd }}$ molar is above the CEJ of $2^{\text {nd }}$ molar.

Position B) When the impacted mandibular $3^{\text {rd }}$ molar is between the alveolar bone and the CEJ of the $2^{\text {nd }}$ molar.

Position C) When impacted mandibular $3^{\text {rd }}$ molar is below the CEJ of the $2^{\text {nd }}$ molar.

\section{Results}

A total number of 655 panoramic radiographs were viewed from patients that presented at two dental clinics, the State House Clinic and QH Specialist Dental Clinics and Research Centre at Gwarinpa, Abuja. There were 97 (14.8\%) patients from the former clinic while 558 (85.2\%) were from the later. There were 366 (55.8\%) males and 289 (44.1\%) females, with an age range of 16 to $70 y e a r s$ and a mean age of $34 \pm 12.5$ years. The panoramic ra- 
diographs were viewed from 477 patients, 30.3\% patients with unilateral impaction and $69.5 \%$ patients with bilateral impaction.

\begin{tabular}{|c|c|c|}
\hline & Frequency & Percent \\
\hline Male & 366 & 55.9 \\
\hline Female & 289 & 44.1 \\
\hline Total & 655 & 100.0 \\
\hline
\end{tabular}

Table 1: Sex Distribution among the Participants in the Study

\section{Discussion}

In this study, among the 655 radiographs viewed, females with $3^{\text {rd }}$ molar impaction accounted for $44.1 \%$ while male accounted for

\begin{tabular}{|c|c|c|}
\hline & Frequency & Percent \\
\hline Single Impaction & 199 & 30.4 \\
\hline Double Impaction & 456 & 69.6 \\
\hline & 655 & 100.0 \\
\hline
\end{tabular}

Table 2: Single and double mandibular $3^{\text {rd }}$ molar impaction. в: Bilateral impaction (double) was more at $69.5 \%$.

\begin{tabular}{|c|c|c|c|c|c|c|c|c|}
\hline \multirow{2}{*}{\multicolumn{3}{|c|}{$\begin{array}{c}\text { Vertical } \\
\text { Mesioangular }\end{array}$}} & \multicolumn{5}{|c|}{ Winter's Classification } & \multirow{3}{*}{$\begin{array}{c}\text { Total } \\
366\end{array}$} \\
\hline & & & \multirow{2}{*}{$\begin{array}{c}\text { Distoangular } \\
107\end{array}$} & \multirow{2}{*}{$\begin{array}{c}\text { Horizontal } \\
159\end{array}$} & \multirow{2}{*}{$\begin{array}{c}\text { Buccolingual } \\
52\end{array}$} & \multirow[b]{2}{*}{39} & \multirow[b]{2}{*}{9} & \\
\hline \multirow{4}{*}{ Sex } & & Count & & & & & & \\
\hline & Male & $\begin{array}{c}\% \\
\text { within } \\
\text { Sex }\end{array}$ & $29.2 \%$ & $43.4 \%$ & $14.2 \%$ & $10.7 \%$ & $2.5 \%$ & $100.0 \%$ \\
\hline & & Count & 108 & 118 & 39 & 18 & 6 & 289 \\
\hline & Female & $\begin{array}{c}\% \\
\text { within } \\
\text { Sex }\end{array}$ & $37.4 \%$ & $40.8 \%$ & $13.5 \%$ & $6.2 \%$ & $21 \%$ & $100.0 \%$ \\
\hline \multirow{2}{*}{\multicolumn{2}{|c|}{$\begin{array}{l}\text { Total } \\
\text { \% within Sex }\end{array}$}} & Count & 215 & 277 & 91 & 57 & 15 & 655 \\
\hline & & $32.8 \%$ & $42.3 \%$ & $13.9 \%$ & $8.7 \%$ & $2,3 \%$ & $100.0 \%$ & \\
\hline
\end{tabular}

Table 3: Winter's classification.

For both sexes, mesioangular impaction was the most common type of $3^{\text {rd }}$ molar impaction recorded and this was followed by vertical impaction. The male had more mesioagular impaction at $43.4 \%$ than the female. Buccolingual impaction was the least for both sexes.

$55.8 \%$, thus the recorded number of $3^{\text {rd }}$ molar impaction as shown on radiographs were more in males than females. While no clear reason can be attributed for this increase in number of males, this report however agrees with the report of Stanley., et al. who recorded more $3^{\text {rd }}$ molar impaction in males and ascribed it to his facility being more accessible to males [26]. Eighty-five per cent of the patients in this study are from a private facility where cost of treatment is high [26], hence the record of attendance of male were more since they are more likely to be employed compared to the females and were thus able to afford the cost of treatment. On the other hand, some authors have reported a female majority in the number of $3^{\text {rd }}$ molar impaction [27-29] and this has been credited partly to the female's lower tolerance of dental pain which makes them to seek early dental care more frequently than males [1,33]. In addition, it is believed that females usually stop growing when the $3^{\text {rd }}$ molar just begin to erupt while the mandible of the male continues to grow during the eruption of the $3^{\text {rd }}$ molar thereby creating more space for the $3^{\text {rd }}$ molar to properly erupt in the man- 


\begin{tabular}{|c|c|c|c|c|c|c|}
\hline & $\begin{array}{c}\text { Position } \\
1\end{array}$ & $\begin{array}{c}\text { Position } \\
2\end{array}$ & $\begin{array}{c}\text { Position } \\
3\end{array}$ & Total \\
\hline \multirow[t]{4}{*}{ Sex } & \multirow[t]{2}{*}{ Male } & Count & 101 & 218 & 47 & 366 \\
\hline & & $\begin{array}{c}\% \text { within } \\
\text { Sex }\end{array}$ & $27.6 \%$ & $59.6 \%$ & $12.8 \%$ & $100.0 \%$ \\
\hline & \multirow[t]{2}{*}{ Female } & Count & 95 & 180 & 14 & 289 \\
\hline & & $\begin{array}{c}\% \text { within } \\
\text { Sex }\end{array}$ & $32.9 \%$ & $62.3 \%$ & $4.8 \%$ & $100.0 \%$ \\
\hline \multirow{2}{*}{\multicolumn{2}{|c|}{$\begin{array}{l}\text { Total } \\
\% \text { within Sex }\end{array}$}} & Count & 196 & 398 & 61 & 655 \\
\hline & & $29.9 \%$ & $60.8 \%$ & $9.3 \%$ & $100.0 \%$ & \\
\hline
\end{tabular}

Table 4: Pell and Gregory Ramus relation.

Position 2 at $62.3 \%$ was the highest position based on Ramus relation and it was found more in females while position 3 was

higher in males than females. The total count had $60.8 \%$ in position 2 as the highest in this study.

\begin{tabular}{|c|c|c|c|c|c|c|}
\hline & $\begin{array}{c}\text { Occlusal } \\
\text { A }\end{array}$ & $\begin{array}{c}\text { Occlusal } \\
\text { B }\end{array}$ & $\begin{array}{c}\text { Occlusal } \\
\mathrm{C}\end{array}$ & Total \\
\hline \multirow[t]{4}{*}{ Sex } & \multirow[t]{2}{*}{ Male } & Count & 261 & 74 & 31 & 366 \\
\hline & & $\begin{array}{c}\text { \% within } \\
\text { Sex }\end{array}$ & $71.3 \%$ & $20.2 \%$ & $8.5 \%$ & $100.0 \%$ \\
\hline & \multirow[t]{2}{*}{ Female } & Count & 203 & 74 & 12 & 289 \\
\hline & & $\begin{array}{c}\text { \% within } \\
\text { Sex }\end{array}$ & $70.2 \%$ & $25.6 \%$ & $4.2 \%$ & $100.0 \%$ \\
\hline \multirow{2}{*}{\multicolumn{2}{|c|}{$\begin{array}{l}\text { Total } \\
\% \text { within Sex }\end{array}$}} & Count & 464 & 148 & 43 & 655 \\
\hline & & $70.8 \%$ & $22.6 \%$ & $6.6 \%$ & $100.0 \%$ & \\
\hline
\end{tabular}

Table 5: Pell and Gregory occlusal relation.

Occlusal $\mathrm{A}$ and $\mathrm{C}$ were both higher in males at $71.3 \%$ and $8.5 \%$ respectively while occlusal $B$ was higher in females at $25.6 \%$ than in males. Occlusal A was recorded as the highest occlusal relationship in this study at $70.8 \%$.

dible of males [18]. Nevertheless, other authors have also reported no gender differences in lower $3^{\text {rd }}$ molar impaction in some population $[1,18,33]$. Also recorded here with OPG was more bilateral $3^{\text {rd }}$ molar impaction (69.5\%) than unilateral impaction (30.3\%). This result agrees with the result of Khan., et al. [10] who reported bilateral impactions in $70 \%$ of cases using both periapical radiographs and orthopantomograms. Possible explanation for having more bilateral impaction than unilateral explanation could be due to lack of space that originally caused the $3^{\text {rd }}$ molar impaction, and this lack of space is not limited to one side of the mandible alone but occurs on both sides [10].

The mesioangular type of $3^{\text {rd }}$ molar impaction was found to be the most common impaction in our study, although this was not statistically significant in relation to sex. Nevertheless, this finding is in consonance with previous studies that gave reports where periapical radiographs were examined $[1,14,18]$ and OPG were used $[5,12,15,16,18]$. While Stanley., et al. [26] and Benediktsdottir., et al. [33] both reported that the vertical impactions were the most common type of mandibular $3^{\text {rd }}$ molar impaction in their studies using periapical radiographs, our study on the other hand, using the OPG recorded the vertical impaction at $32.8 \%$ as the second most common type of $3^{\text {rd }}$ impaction. Using the Pell and Gregory's Classification [9] Position 2 was found as the most common position $(60.8 \%)$ however, this was not statistically significant in this study. Position 1 was recorded 29.9\% while Position 3 was found in 9.3\% of our OPG. This result agrees with similar findings in which the OPG were used by Khan., et al. [10], Hashemipour., et al. [12], Almendros-Marques., et al. [34] but disagrees with the report of Obiechina., et al. [35] who used periapical.

Occlusal level A was the most common depth of impaction in this study at $70.8 \%$, and this also was no statistically significant in this study. This was followed by occlusal level B at $22.6 \%$ and occlusal level $\mathrm{C}$ at $6.6 \%$. This result is however different from that of Eshghpour., et al. [5], Khan., et al. [10], Hassan [13], Quek., et al. [15], Almendros-Marqués., et al. [34] and Biu., et al. [36] who all used the OPG and reported Level B depth as the most common in their studies. Hashemipour., et al. [12] using the OPG agrees with Obiechina., et al. [35] who used periapical radiographs, both reported occlusal level $\mathrm{C}$ as the most common occlusal level in their studies. It has been argued that these different findings from various authors could have arisen because some researchers evaluate the $3^{\text {rd }}$ molar impaction level from the CEJ of the $2^{\text {nd }}$ molar in relation to the alveolar bone level excluding the erupted $3^{\text {rd }}$ molar while others evaluated according to the relationship of the occlusal surfaces of the $3^{\text {rd }}$ molar and the CEJ of adjacent $2^{\text {nd }}$ molar [5]. In this study, evaluation was done according to the relationship of the occlusal level of the $3^{\text {rd }}$ molar with the CEJ of the $2^{\text {nd }}$ molar. 


\section{Conclusion}

This study has reported on the radiographs from the OPG of a large population describing the impaction pattern observed. A few differences were noticed in impaction patterns of other studies especially where the periapical radiographs were use, but majority of our observations were in consonance with studies from other parts of the world where OPG were also used. Our results being different when the OPG was used could have been from the clarity and broad view we got while viewing panoramic radiographs produced by the OPG. For better treatment predictability and outcome, requesting for an OPG before any impacted mandibular $3^{\text {rd }}$ molar extraction is done, should be the golden standard.

\section{Conflict of Interest}

None to declare.

\section{Acknowledgement}

The efforts of Dr Adeoye John Ademola for making out time to review the statistics.

\section{Bibliography}

1. Osunde OD and Bassey GO. "Pattern of impacted mandibular third molars in Calabar, Nigeria". African Journal of Medical and Health Sciences 15 (2016): 14-17.

2. Alling CC and Catone GA. "Management of impacted teeth". Journal of Oral and Maxillofacial Surgery 51.1-1 (1993): 3-6.

3. Peterson LJ., et al. "Contemporary Oral and Maxillofacial Surgery". $2^{\text {nd }}$ edition. Missouri: Mosby (1993): 225-260.

4. Ma'aita J and Alwrikat A. "Is the mandibular third molar a risk factor for mandibular angle fracture?" Oral Surgery, Oral Medicine, Oral Pathology, and Oral Radiology 89.2 (2000): 143-146.

5. Eshghpour M., et al. "Pattern of mandibular third molar impaction: A cross-sectional study in northeast of Iran". Nigerian Journal of Clinical Practice 17.6 (2014): 673-677.

6. Eshghpour M., et al. "Effect of menstrual cycle on frequency of alveolar osteitis in women undergoing surgical removal of mandibular third molar: a single-blind randomized clinical trial". Journal of Oral and Maxillofacial Surgery 71.9 (2013): 1484-1489.
7. Bello SA., et al. "A randomized comparison of the effect of partial and total wound closure techniques on postoperative morbidity after mandibular third molar surgery". Journal of Oral and Maxillofacial Surgery 69.6 (2011): e24-30.

8. Winter GB. "Principles of exodontias as applied to the impacted third molar 1st ed". St. Louis American medical books 1926. In Contemporary Oral and Maxillofacial Surgery. 2nd edition. Edited by: Peterson LJ., et al. (1993): 225-260.

9. Pell GJ and Gregory BT. "Impacted mandibular third molars: classification and modified techniques for removal". Dental Digest 19 (1933): 430.

10. Khan MA., et al. "Frequency of Different Types of Mandibular Third Molar Impactions". International Journal of Medical Research and Health Sciences 8.6 (2019): 120-124.

11. Bello SA., et al. "Effect of age, impaction types and operative time on inflammatory tissue reactions following lower third molar surgery". Head and Face Medicine 7 (2011): 8.

12. Hashemipour MA., et al. "Incidence of impacted mandibular and maxillary third molars: A radiographic study in a Southeast Iran population". Medicina Oral, Patologia Oral, Cirugia Bucal 18 (2013): e140-145.

13. Hassan AH. "Pattern of third molar impaction in a Saudi population". Clinical, Cosmetic and Investigational Dentistry 2 (2010): 109-113.

14. Passi D., et al. "Study of pattern and prevalence of mandibular impacted third molar among Delhi-National Capital Region population with newer proposed classification of mandibular impacted third molar: A retrospective study". National Journal of Maxillofacial Surgery 10.1 (2019): 59-67.

15. Quek SL., et al. "Pattern of third molar impaction in a Singapore Chinese population: A retrospective radiographic survey". The International Journal of Oral and Maxillofacial Surgery 32 (2003): 548-552.

16. Msagati F., et al. "Pattern of occurrence and treatment of impacted teeth at the Muhimbili National Hospital, Dar es Salaam, Tanzania". BMC Oral Health 13 (2013): 37. 
17. Gbotolorun OM., et al. "Impacted mandibular third molars: presentation and postoperative complications at the Lagos University Teaching Hospital". Nigerian Quarterly Journal of Hospital Medicine 17.1 (2007): 26-29.

18. Adelusi EA and Okoje VN. "Pattern of Mandibular Third Molar Presentation: Ten Years' Experience at the University College Hospital Ibadan”. Dentistry 8 (2018): 516.

19. Osunde OD., et al. "A comparative study of the effect of sutureless and multiple suture techniques on inflammatory following third molar surgery". The International Journal of Oral and Maxillofacial Surgery 41 (2012): 1275-1279.

20. Kanazirska PG., et al. "Comparison of diagnostic capabilities of Orthopantomography and Cone beam computed tomography in determining the topographic relationship between impacted mandibular third molars and mandibular channel". Journal of IMAB 23.2 (2017): 1546-1549.

21. De Melo Albert DG., et al. "Comparison of orthopantomographs and conventional tomography images for assessing the relationship between impacted lower third molars and the mandibular canal". Journal of Oral and Maxillofacial Surgery 64.7 (2006): 1030-1037.

22. Lübbers HT., et al. "Anatomy of impacted lower third molars evaluated by computerized tomography: is there an indication for 3-dimensional imaging?" Oral Surgery, Oral Medicine, Oral Pathology, and Oral Radiology 111.5 (2011): 547-550.

23. Nakayama K., et al. "Assessment of the relationship between impacted mandibular third molars and alveolar inferior nerve with dental 3-dimensional computed tomography". Journal of Oral and Maxillofacial Surgery 67.12 (2009): 2587-2259.

24. Suomalainen A., et al. "Reliability of CBCT and other radiographic methods in preoperative evaluation of lower third molars". Oral Surgery, Oral Medicine, Oral Pathology, and Oral Radiology 109.2 (2010): 276-284.

25. Alfadil I and Almajed E. "Prevalence of impacted third molars and the reason for extraction in Sausi Arabia". The Saudi Dental Journal 32.5 (2020): 262-268.
26. Stanley HR., et al. "Pathological sequelae of "neglected" impacted third molars". Journal of Oral Pathology and Medicine 17 (1988): 113-117.

27. Akinwande JA. "Mandibular third molar impaction-A comparison of two methods for predicting surgical difficulty". Nigerian Dental Journal 10 (1991): 3-7.

28. Seward GR., et al. "An outline of Oral Surgery Part 1". $2^{\mathrm{ND}}$ edition. Bombay. Varghese Publishing House; (1988): 52-70.

29. Santamaria J and Arteagoitia I. "Radiologic variables of important clinical significant in the extraction of impacted mandibular third molars". Oral Surgery, Oral Medicine, Oral Pathology, and Oral Radiology 84 (1997): 469-473.

30. Colorado-Bonnin M., et al. "Quality of life following lower third molar removal". International Journal of Oral and Maxillofacial Surgery 35 (2006): 343-347.

31. Kim JC., et al. "Minor complications after mandibular third molar surgery: Type, incidence, and possible prevention". Oral Surgery, Oral Medicine, Oral Pathology, and Oral Radiology 102 (2006): e4-11.

32. Hattab FN., et al. "Impaction status of third molars in Jordanian students". Oral Surgery, Oral Medicine, Oral Pathology, and Oral Radiology 79 (1995): 24-29.

33. Benediktsdóttir IE., et al. "Mandibular third molar removal: Risk indicators for extended operation time, postoperative pain, and complications". Oral Surgery, Oral Medicine, Oral Pathology, and Oral Radiology 79 (2004): 434-446.

34. Almendros-Marqués N., et al. "Factors influencing the prophylactic removal of asymptomatic impacted lower third molars". International Journal of Oral and Maxillofacial Surgery 37 (2008): 29-35.

35. Obiechina AE., et al. "Third molar impaction: Evaluation of the symptoms and pattern of impaction of mandibular third molar teeth in Nigerians". Odonto-Stomatologie Tropicale 24 (2001): 22-25. 
36. Bui CH., et al. "Frequencies, and risk factors for complications after third molar extraction". Journal of Oral and Maxillofacial

Surgery 61.12 (2003): 1379-1389.

\section{Assets from publication with us}

- Prompt Acknowledgement after receiving the article

- Thorough Double blinded peer review

- Rapid Publication

- Issue of Publication Certificate

- High visibility of your Published work

Website: www.actascientific.com/

Submit Article: www.actascientific.com/submission.php

Email us: editor@actascientific.com

Contact us: +919182824667 